\title{
Botos bons, peixes e pescadores: sobre a pesca conjunta em Laguna (Santa Catarina, Brasil)
}

\author{
[ "Good dolphins", fishes and fishermen: about the conjoint \\ fishing in Laguna (Santa Catarina, Brazil)
}

\section{Brisa Catão ${ }^{\mathrm{I}}$}

\section{Gabriel Coutinho Barbosa²}

Esta pesquisa contou com apoio financeiro da Coordenação de Aperfeiçoamento de Pessoal de Nível Superior (Capes), do Programa de Pós-Graduação em Antropologia e Arqueologia da Universidade Federal de Minas Gerais (PPGAN-UFMG) e do Instituto Brasil Plural (IBP-INCT).

\begin{abstract}
RESUMO - Em Laguna (Santa Catarina, Brasil), pescadores artesanais e golfinhos-nariz-degarrafa desenvolvem formas peculiares de pescar juntos. "Botas boas” e "botos bons" (como são conhecidos os animais que participam da pesca) conduzem cardumes de tainhas em direção aos pescadores, sinalizam a localização dos peixes e o momento certo de lançar as tarrafas. Este artigo apresenta uma descrição geral dessa pesca, abordando as relações entre botos, pescadores e peixes, os conhecimentos dos pescadores sobre os golfinhos, a comunicação entre eles, bem como a coaprendizagem e o desenvolvimento interespecífico de habilidades entre botos e pescadores. PALAVRAS-CHAVE - Pesca; golfinhos; comunicação; coaprendi-
\end{abstract}

zagem; habilidades. • ABSTRACT · In Laguna (Santa Catarina, Brazil), artisanal fishermen and bottlenose dolphins have developed peculiar ways of fishing together. "Good dolphins" (as the animals that are involved in fishing are known) lead schools of mullets to the fishermen and signal the location of the fish and the timing for throwing the nets. This article presents a general description of this fishing, exploring the relations among dolphins, fishermen and fish, the fishermen's knowledge about dolphins, the communication between them, as well as the co-learning and the interspecific development of skills among dolphins and fishermen. KEYWORDS · Fishing; dolphins; communication; co-learning; skills.

Recebido em 9 de dezembro de 2017

Aprovado em 6 de fevereiro de 2017

CATÃO, Brisa; BARBOSA, Gabriel Coutinho. Botos bons, peixes e pescadores: sobre a pesca conjunta em Laguna (Santa Catarina, Brasil). Revista do Instituto de Estudos Brasileiros, Brasil, n. 69, p. 205-225, abr. 2018.

DOI: http://dx.doi.org/Io.II6o6/issn.23I6-90IX.voi69p205-225

I Universidade Federal de Minas Gerais (UFMG, Belo Horizonte, MG, Brasil).

2 Universidade Federal de Santa Catarina (UFSC, Florianópolis, SC, Brasil). 


\section{APRESEnTAÇÃo}

Há pelo menos I70 anos, em Laguna (Santa Catarina, Brasil), golfinhos e pescadores desenvolvem criativas formas de pescar juntos. Tais práticas são conhecidas na cidade como tarrafear no boto ${ }^{3}$, variando entre o salto e a batida. Nelas, certos golfinhos conduzem cardumes de tainhas em direção aos pescadores, sinalizando com movimentos corporais a localização dos peixes e o momento oportuno para lançar as tarrafas. "O boto bom traz o peixe para o pescador", dizem os tarrafeadores. Estes conhecem muito bem os animais que colaboram com eles: reconhecem-lhes individualmente, atribuem-lhes nomes, conhecem seus hábitos particulares de pesca e acontecimentos em suas histórias de vida, como relações de parentesco e episódios de emalhe.

Neste artigo apresentamos uma descrição geral da pesca, resultados parciais e hipóteses com base em investigação bibliográfica e etnográfica. As reflexões apresentadas são fruto de uma longa interlocução entre os autores e parte de uma pesquisa de doutorado em andamento 4 . Os períodos de trabalho de campo concentraram-se nos invernos de 2015 e 20I6, no ponto de pesca chamado Tesoura. Localizado nas margens do canal de Laguna, ele está a apenas quatro quilômetros do centro da cidade. Tudo se passa, portanto, em contexto urbano. Tal atividade acontece durante todo o ano, mas sobretudo na temporada das tainhas ${ }^{5}$ ou safra, entre meados de abril e final de junho.

3 No Brasil, boto é uma designação genérica para diferentes mamíferos aquáticos das famílias Delphinidae e Iniidae, que habitam oceanos, rios, canais e lagoas. Em Laguna, os pescadores costumam usar bota para designar boto-fêmea, alternativa adotada neste artigo. Expressões locais e ênfases dos autores são grafadas em itálico ao longo do texto.

4 Agradecemos a Eduardo Viana Vargas pela orientação da pesquisa de doutorado, a Deborah Lima, Rogério Brittes, Viviane Vedana, Rafael V. Devos, Stelio Marras e Joana Cabral; a Thom van Dooren pelo acolhimento durante o doutorado-sanduíche; aos amigos do Laboratório de Antropologia das Controvérsias Sociotécnicas (LACS/UFMG) e do Coletivo de Estudos em Ambientes, Percepções e Práticas (Canoa/UFSC).

5 Diferentes espécies de peixes da família dos mugilídeos são designadas “tainhas”. Em Laguna, trata-se de Mugil spp. 


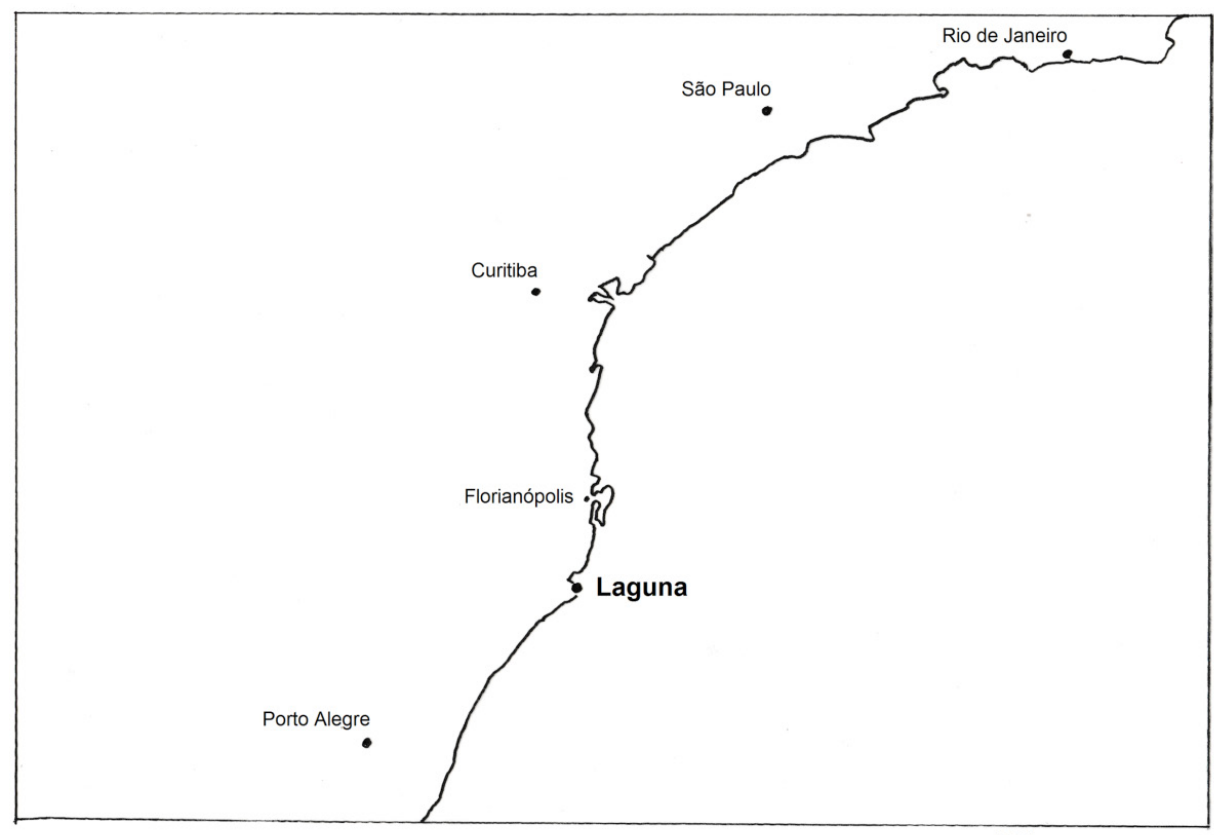

Figura I - Localização de Laguna. Mapa: Gabriel Coutinho Barbosa

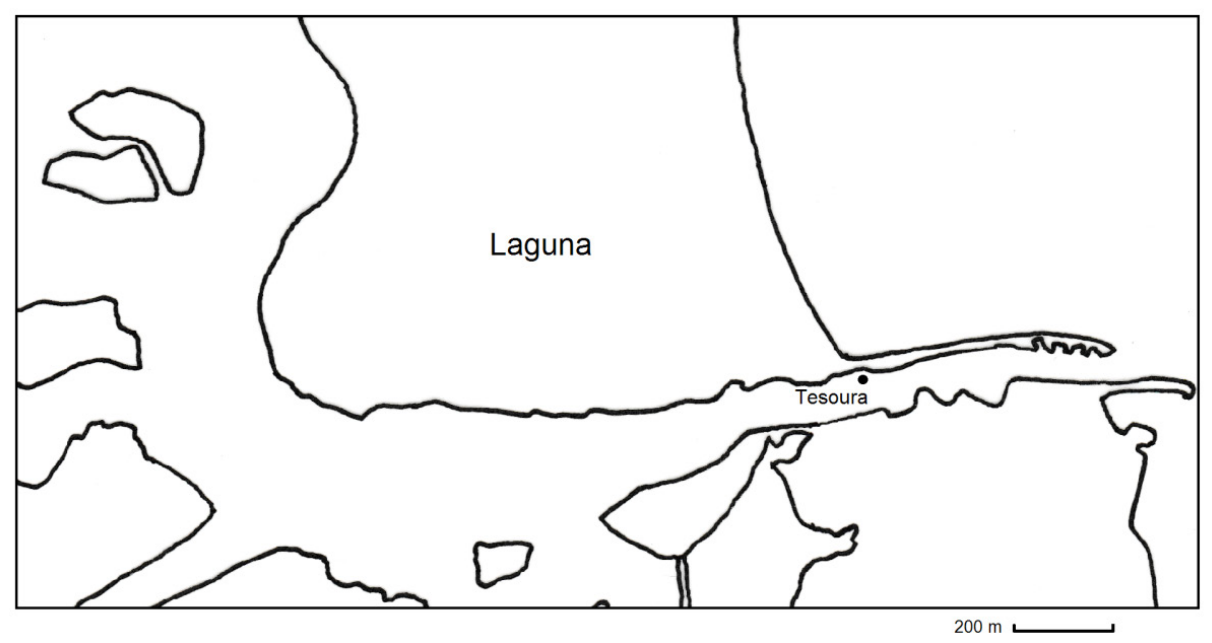

Figura 2 - Localização da Tesoura. Mapa: Gabriel Coutinho Barbosa

Como praticamente toda literatura sobre essa pesca advém das ciências biológicas, um dos desafios é compreender essa interação interespecífica desde 
um outro ponto de vista: o antropológico ${ }^{6}$. Todavia, não se trata de investigar como tal experiência é significada pelos pescadores locais no interior de sua cultura, relegando o comportamento de golfinhos e peixes a objetos de estudo de outras áreas do conhecimento. Nosso foco não é um grupo específico de pescadores, tampouco um grupo determinado de peixes ou golfinhos, mas aquilo que Dominique Lestel e colaboradoras7 chamam de "comunidades híbridas", em que animais humanos e não humanos compartilham significados, interesses e afetos.

\section{UM DIA TÍPICO DE INVERNO NA TESOURA}

É inverno e a água está fria ou gelada. Perfilados com a água na altura da cintura ou do peito, com as tarrafas enroladas e suspensas nas mãos, os pescadores aguardam um sinal. Ventos fortes, chuvas, variações de temperatura e incidência solar atravessam a estação, tornando indispensáveis o uso de certos acessórios, sobretudo do macacão impermeável com botas de borracha acopladas, que possibilitam aos pescadores permanecer na água por longos períodos. Embora os golfinhos visitem

6 PRYOR, K. et al. A dolphin-human fishing cooperative in Brazil. Marine Mammalogy Science, n. 6, I990, p. 325-332; SIMÕES-LOPES, P. C. Interaction of coastal populations of Tursiops truncatus (Cetacea, Delphinidae) with the mullet artisanal fisheries in Southern Brazil. Biotemas, n. 4, I99I, p. 83-94; SIMÕES-LOPES, P. C.; FÁBIAN, M. E.; MENEGHETI, J. O. Dolphin interactions with the mullet artisanal fishing on Southern Brazil: a qualitative and quantitative approach. Revista Brasileira de Zoologia, n. I5, I998, p. 709-726; SIMÕES-LOPES, P. C.; DAURA-JORGE, F.; CANTOR, M. Clues of cultural transmission in cooperative foraging between artisanal fishermen and bottlenose dolphins, Tursiops truncatus (Cetacea: Delphinidae). Zoologia, v. 33, 20I6, n. 6; PRZBYLSKI, C. B.; MONTEIRO-FILHO, E. L. A. Interações entre pescadores e mamíferos marinhos no litoral do estado do Paraná - Brasil. Biotemas, v. I4, n. 2, 200I, p. I4I-I56; PETERSON, D. Etnobiologia dos botos (Tursiops truncatus) e a pesca cooperativa em Laguna, Santa Catarina. Monografia (Bacharelado em Ciências Biológicas). Universidade Federal de Santa Catarina, 2005; PETERSON, D.; HANAZAKI, N.; SIMÕES-LOPES, P. C. Natural resource appropriation in cooperative artisanal fishing between fishermen and dolphins (Tursiops truncatus) in Laguna, Brazil. Ocean Coast Manag., n. 5, 2008, p. 469-475; ZAPPES, C. et al. "Human-dolphin (Tursiops truncatus Montagu, I82I) cooperative fishery" and its influence on cast net fishing activities in Barra de Imbé/Tramandaí, Southern Brazil. Ocean er Coastal Management, n. 54, 20II, p. 427-432; DAURA-JORGE, F.G. Quantos? Onde? Como? Múltiplos aspectos ecológicos de uma população do boto-da-tainha (Tursiops truncatus) em Laguna, sul do Brasil: implicações para conservação. Tese (Doutorado em Zoologia). Programa de Pós-Graduação em Ciências Biológicas - Zoologia, Universidade Federal do Paraná, 20II; ROMEU, B. Repertório acústico do boto-da-tainha no contexto da pesca cooperativa com pescadores artesanais em Laguna, sul do Brasil. Monografia (Bacharelado em Ciências Biológicas). Universidade Federal de Santa Catarina, 20ı2; ROMEU, B. Contribuições do comportamento acústico do boto-da-tainha (Tursiops truncatus) para o entendimento da interação entre botos e pescadores em Laguna, Santa Catarina. Dissertação (Mestrado em Ecologia). Universidade Federal de Santa Catarina, 20I5. Fora das ciências naturais, a exceção encontrada é: IINO, F. S. Pescadores artesanais na Praia da Tesoura, Laguna/SC: reflexões sobre sociabilidades e apropriações do espaço. Dissertação (Mestrado em Antropologia Social). Universidade Federal de Santa Catarina, 2017.

7 LESTEL, D.; BRUNOIS, F.; GAUNET, F. Etho-ethnology and ethno-ethology. Social Science Information, v. 45, n. 2, 2006, p. I55-I77. 
a Tesoura diversas vezes em um único dia, as jornadas e a espera dos pescadores podem ser extenuantes. Fora d'água, outros homens limpam e vendem peixes, fazem e reparam as tarrafas, esperando a vez de fazer a vaga, que são as posições dentro d'água, ocupadas por ordem de chegada.

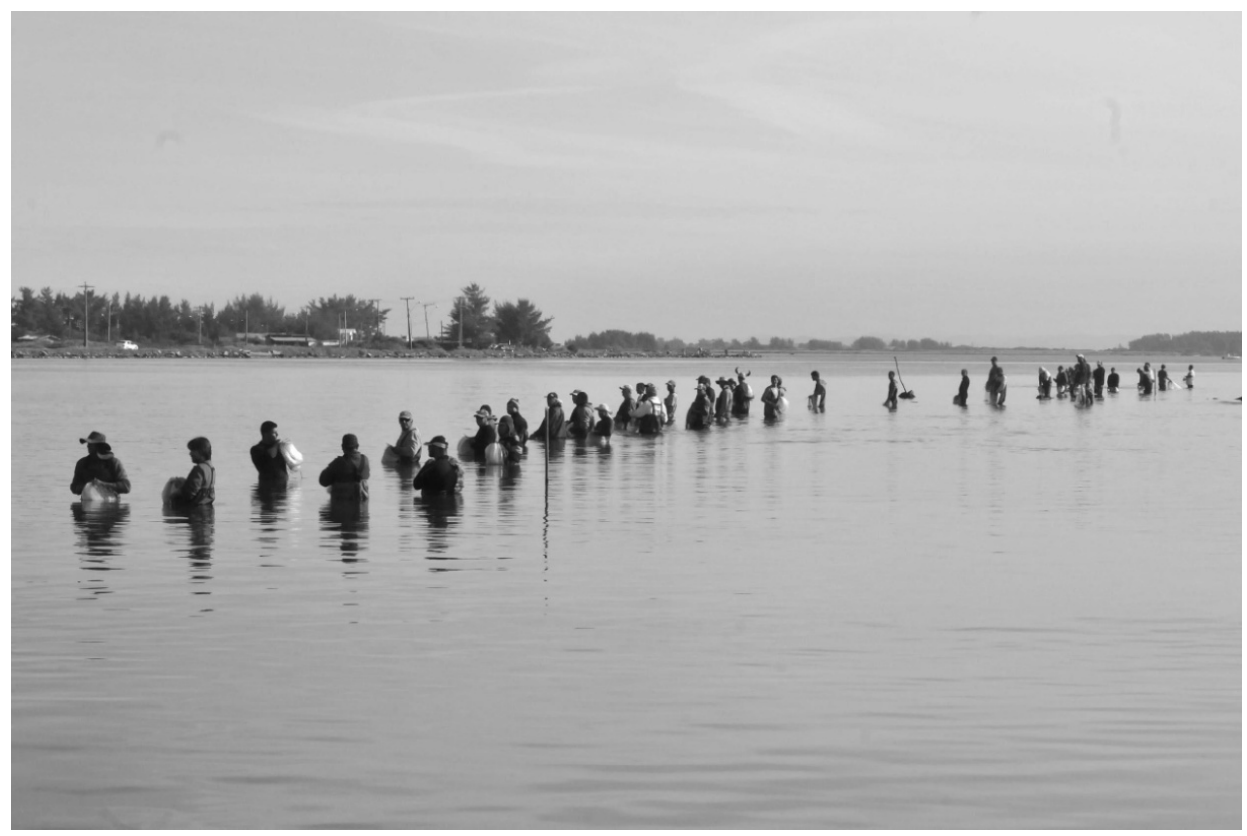

Figura 3- Pescadores na linha d'água (inverno 20I6). Foto: Brisa Catão

Quando os botos aparecem, em grupos, duplas ou sozinhos, o ritmo local muda. A atmosfera de espera e descontração torna-se ligeiramente apreensiva. Sempre em movimento, entre mergulhos e reaparições intermitentes, os botos submergem, desaparecem nas águas turvas do canal e voltam a emergir adiante. Os pescadores acompanham os botos, procurando antever onde eles ressurgirão a cada vez. $\mathrm{Da}$ areia e da linha d'água, seguimos seus deslocamentos observando as nadadeiras dorsais e os borrifos d'água lançados pelos orifícios respiratórios. Todos se engajam atentamente no lance, cujo desfecho nunca é completamente previsto.

Debaixo d'água, as tainhas refugiam-se em meio às pedras no fundo e nas laterais do canal. A conduta mais comum é os botos as aguardarem, mantendo-se discretamente perto dos alagados (aglomerações de pedras submersas), cheirando peixe, boiando, disfarçando, de barriga para cima.

Quando as tainhas deixam as pedras, inicia-se o cerco. Um ou mais botos passam a afugentar os peixes em direção aos pescadores. Quando o cardume encontra-se ao alcance de alguma tarrafa, o boto ou a bota executa um movimento característico para mostrar peixe aos pescadores. 


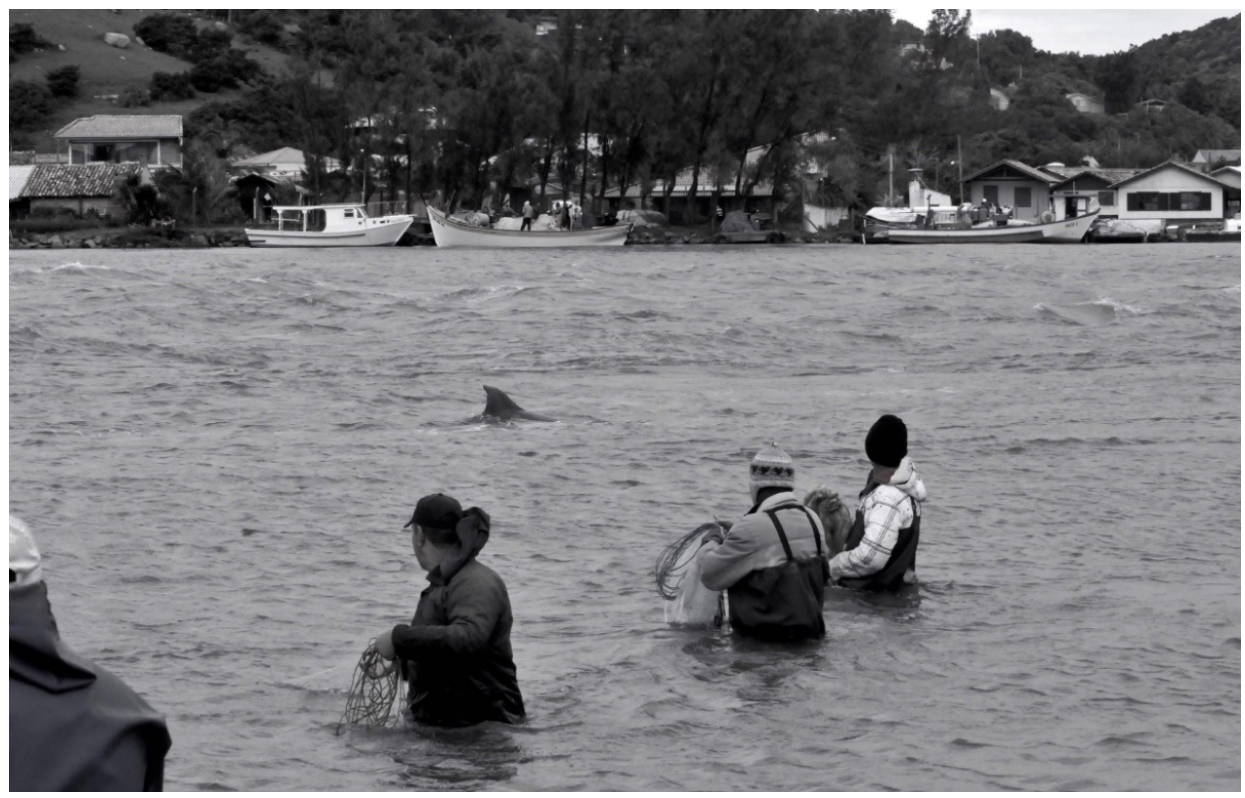

Figura 4-Um(a) boto(a) se aproxima (inverno 20I6). Foto: Brisa Catão

É o momento tão esperado, quando os homens devem arremessar suas redes. O primeiro a fazê-lo é aquele na vaga em frente à sinalização do animal. Em seguida, é a vez daqueles que estão imediatamente ao seu lado lançarem as tarrafas de fora ou do recurso. Cada sinalização de um golfinho desencadeia uma sequência de movimentos quase coreografados de torções de troncos e estiramentos de braços para arremesso das tarrafas.

Após um lanço bem-sucedido, o pescador arrasta cuidadosamente a sua rede até a faixa de areia. Sozinho ou com a ajuda de um parceiro, ele retira a tarrafa da água e começa a despescar, desprendendo os peixes da malha, conferindo a quantidade e a qualidade das tainhas capturadas. $O$ boto que mostrou o cardume pode continuar por ali trabalhando ou ir embora lagoa adentro ou mar afora. Algum tempo depois, outros chegarão e a captura recomeçará.

\section{“O QUE OS BOTOS GANHAM COM ISSO?”}

Essa tem sido a mais frequente pergunta, da parte de diferentes interlocutores, diante do que se passa em Laguna. De acordo com biólogos especialistas na "pesca cooperativa das tainhas", como a atividade é designada, trata-se de "forrageio cooperativo". Os pescadores têm acesso a mais peixes, beneficiando-se dos cardumes conduzidos pelos golfinhos e da sinalização de sua localização em águas turvas. Os golfinhos usariam a barreira de homens como anteparo no cerco às tainhas e a desorganização dos cardumes provocada pelas tarrafas lançadas para capturar mais

8 SIMÕES-LOPES, P. C.; DAURA-JORGE, F.; CANTOR, M., op. cit. 
facilmente os peixes desnorteados. Desse modo, uns e outros obteriam recursos de forma mais vantajosa, otimizando gasto e consumo energéticos.

A cada arremesso de tarrafa os pescadores podem obter de nenhum a mais de 200 peixes. Eles mesmos afirmam: "sem o boto, a gente não pega nada". Na ausência desses, pescadores tarrafeiam às cegas ou avistam peixe, atentos a sinais das tainhas: restolhos na água, manchas de cardume, reflexos de escamas.

Biólogos, pescadores e demais moradores de Laguna multiplicam as hipóteses sobre as motivações dos botos e suas formas de participação na pesca. Alguns pescadores dizem: "tem dias que o boto está mais para trabalhar para o pescador do que para comer. Salta em uma, duas, três mantas de peixe e não come nenhum”. Outros defendem que os botos agem em benefício próprio: "o boto salta para comer e o pescador bem intrometido bota a tarrafa no meio" ".o. Há relatos sobre os botos levantarem as bordas da tarrafa submersa para pegar peixes enredados. "Nem todos os botos roubam na tarrafa. E nem tudo que eles roubam, eles comem. Roubam para soltar, para comer, às vezes para roubar de novo"I.

Variam, assim, as hipóteses sobre a participação e as motivações de botas e botos bons. No entanto, é uma falsa alternativa que nos faz perguntar: os botos estão agindo em benefício próprio ou dos pescadores? Seus comportamentos são altruístas ou egoístas? Altruísmo ou egoísmo, cooperação ou oportunismo, a preocupação de fundo a tal qualificação parece ser sempre de ordem econômica ou utilitária. Qual a vantagem em participar dessa relação? O que pescadores e, sobretudo, os golfinhos ganham com isso? $\mathrm{O}$ fenômeno possui complexidades que desaparecem ou se tornam secundárias quando as questões são colocadas nestes termos. O problema, então, está não na diversidade das respostas, mas nas próprias perguntas. Aparentemente simples, elas guardam equívocos terminológicos, perversidades dualistas e simplificações de situações de cooperação.

A esse respeito, Thom van Dooren e Vinciane Despret ressaltam diferentes entendimentos das noções de "egoísmo" e "altruísmo" um comportamento é considerado egoísta ou altruísta independente de o sujeito agir deliberadamente em seu próprio interesse (e sem considerar os demais) ou em benefício de outrem (com custo para si mesmo). Nesse sentido, "selfishness and altruism are not at all concerned with motivations" or cooperative if they evolve to grow in ways that make room for each other" ${ }^{\prime \prime 4}$. Tal diferença

9 Depoimento de Amilton, maio de 2015.

Io Depoimento de Gegê, maio de 2016.

II Depoimento de Safico, junho de 2015.

I2 VAN DOOREN, T.; DESPRET, V. Evolution: lessons from some cooperative ravens. In: TURNER, L.; BROGLIO,

R.; SELLBACHS, U. (Ed.) The Edinburgh companion to animal studies. Edinburgh: University of Edinburgh. No prelo. Disponível em: <thomvandooren.org/papers-in-progress >. Acesso em: jan. 20I8. Citado com a permissão dos autores.

I3 Ibidem, p. 6.

I4 Ibidem, p. 3. 
entre "função" evolutiva e "motivação" psicológica é frequentemente compreendida como aquela entre causas "últimas" e "próximas" ז5.

Diante disso, o que nos parece fundamental é recusar perguntas e respostas que operem em chaves excludentes: ou comida, eficiência e vantagens energéticas e evolutivas ou relação, afetos, interesses e significados compartilhados. Supomos que diferentes arranjos estão envolvidos, variando em contextos e intensidades, entre indivíduos da mesma e de diferentes espécies.

Ao invés de perguntarmos o que botos e pescadores ganham com essa parceria, nos interessa acompanhar como eles se associam de maneiras repletas de sentidos e complexidades. Ao se reunirem em torno dos peixes, pescadores, botas e botos bons (re)pactuam constantemente suas ações, convivências, entendimentos mútuos, desejos e necessidades. Portanto, mais do que apontar o porquê de tal prática, sobretudo do engajamento dos botos, interessa-nos aqui como ela se dá.

\section{EM LAGUNA E ALHURES}

Além da Tesoura, são relatados pelos pescadores outros 25 pontos de pesca na Lagoa Santo Antônio e Foz do Rio Tubarão, onde tal colaboração acontece. A intensidade da pesca nesses locais varia sazonalmente. Em alguns deles pesca-se em pequenas embarcações, em outros, com o corpo dentro d'água. A Tesoura não é um ponto de pesca como todos os outros. Ali, na época do peixe, é onde se têm mais botos e pescadores, tainhas sendo capturadas e comercializadas, moradores e turistas assistindo à atividade. Em decorrência da visitação turística e grande circulação de pessoas, é também onde o pescado atinge os maiores valores comerciais.

No Brasil, o relato aparentemente mais antigo de fenômeno semelhante refere-se à relação entre um boto-cor-de-rosa (Inia geoffrensis) e um pescador, na região amazônica, onde o animal encurralava os peixes e recebia em troca uma parte do pescado $^{\mathrm{I6}}$. Na região de Pipa (RN), Caravelas (BA) e Baía de Guaratuba (PR) também foi relatada a presença de golfinhos encurralando tainhas na direção de redes pesqueiras ${ }^{17}$. Situações semelhantes também foram registradas nos litorais do Rio de Janeiro e São Paulo ${ }^{18}$. Nas proximidades de Laguna, fenômenos similares ocorrem nos rios Araranguá (SC), Mampituba (entre SC e RS) e Tramandaí (RS). Além de interações de pesca com humanos, há relatos de "pescas associativas" entre golfinhos e aves marinhas na região de Cananeia (SP) ${ }^{\text {I. }}$.

I5 DE WAAL, Frans B. M. Putting the altruism back into altruism: the evolution of empathy. Annual Review of Psychology, n. 59, 2008, p. 279-300 apud VAN DOOREN, T.; DESPRET, V., op. cit., p. 7.

I6 LAMB, F. B. The fisherman's porpoise. Nat. Hist., v. 63, n. 5, I954, p. 23I-232 apud PRZBYLSKI, C. B.; MONTEIRO-FILHO, E. L. A., op. cit.

I7 PRZBYLSKI, C. B.; MONTEIRO-FILHO, E. L. A., op. cit.

I8 Ibidem.

I9 MONTEIRO-FILHO, E. Pesca associada entre golfinhos e aves marinhas. Revista Brasileira de Zoologia, v. 9,

n. I-2, I992, p. 29-37. 
Fora do Brasil, há registros de cinco fenômenos semelhantes. Há relatos de cooperação entre golfinhos-nariz-de-garrafa (Tursiops truncatus) e golfinhos-corcunda-do-Atlântico (Sousa teuszii) com os Imraguen, na costa da Mauritânia ${ }^{20}$; entre golfinhos-do-rio-Irrawaddy (Orcaella brevirostris) e pescadores em Mianmar ${ }^{2 \mathrm{I}}$ e na lagoa Chilika (Índia) ${ }^{22}$. Na Austrália, há relatos que descrevem pelo menos duas formas diferentes de colaboração entre golfinhos e humanos nos séculos XIX e XX. A primeira refere-se ao cerco e captura de tainhas e anchovas por povos indígenas e golfinhos-nariz-de-garrafa na Baía Moreton ${ }^{23}$. A segunda, mais impressionante pela magnitude, diz respeito à cooperação entre um grupo de golfinhos orca (Orcinus orca) e baleeiros, aproximadamente entre I840-I930, nas proximidades do porto de Eden ${ }^{24}$.

Trata-se de situações em que golfinhos conduzem (ou conduziam) cardumes de peixes (ou baleias) para baías ou águas rasas, onde pescadores posicionam-se para a captura. Variam, em cada contexto, as espécies e quantidade de indivíduos envolvidos, os artefatos utilizados, as formas de atração dos animais (quando elas existem) e a intensidade da interação. A pesca em Laguna destaca-se pela intensidade, pelo fato de os golfinhos sinalizarem os peixes individualmente e pela acentuada responsividade entre botos e pescadores ${ }^{25}$. Por isso, a sequência de comportamentos de golfinhos e pescadores em Laguna é considerada "altamente ritualizada" ${ }^{26}$.

\section{DANDO NOME AOS BOTOS}

Os botos que participam da pesca em Laguna são cientificamente classificados como Tursiops truncatus, também conhecidos como golfinhos-nariz-de-garrafa ou botos-da-tainha. Para os pescadores, eles são, antes de tudo, botos e botas boas, com características e nomes próprios, como Scooby, Caroba, Jade, Botinha do Rio, Batman,

20 BUSNEL, R. G. Symbiotic relationship between man and dolphins. Transaction New York Acad. Sci., n. 35 , I973, p. II2-I3I.

2I SMITH, B. D. et al. Catch composition and conservation management of a human-dolphin cooperative cast-net fishery in the Ayeyarwady River, Myanmar. Biol. Conserv., n. I42, 2009, p. I042-I049.

22 D'LIMA, C. et al. Positive interactions between irrawaddy dolphins and artisanal fishers in the Chilika Lagoon of Eastern India are driven by ecology, socioeconomics, and culture. Ambio a Journal of the Human Environment, v. 43, n. 5, 2013, p. 614-624.

23 NEIL, D. T. Cooperative fishing interactions between Aboriginal Australians and dolphins in eastern Australia. Anthrozoos, n. I5, 2002, p. 3-I8.

24 CLODE, D. Killers in Eden: the true story of killer whales and their remarkable partnership with the whalers of Twofold Bay. Sydney (Australia): Allen \& Unwin, 2002. Ver: KILLERS of Eden and darkness was upon the face of the deep. Killers of Eden. The incredible true history of the killer whales of Twofold Bay. Disponível em: 〈http://www.killersofeden.com>. Acesso em: I2 fev. 2016.

25 SIMÕES-LOPES, P. C.; DAURA-JORGE, F.; CANTOR, M., op. cit.

26 PRYOR, K. et al., op. cit., p. 326; SIMÕES-LOPES, P. C.; FÁBIAN, M. E.; MENEGHETI, J. O., op. cit., p. 93; PETERSON, D.; HANAZAKI, N.; SIMÕES-LOPES, P. C., op. cit., p. 470; DAURA-JORGE, op. cit., p. 39. 
Eletrônico e tantos outros. Distinguem-se os botos bons e ruins, aqueles que trabalham daqueles que não trabalham na pesca, também chamados de vadios ou turistas. Apenas os primeiros são nomeados pelos pescadores. Quando questionados sobre os demais, a resposta costuma ser: "ah, isso aí é boto ruim!".

Da população total de golfinhos-nariz-de-garrafa residentes na região, cerca de 50 animais, estima-se que aproximadamente 25 são botos bons ou "botos cooperados" ${ }^{27}$. Os pescadores fornecem número muito semelhante, identificando sexo, idade aproximada, filiação materna, características físicas (tamanho, coloração, formato da nadadeira dorsal e marcas no corpo), padrões de comportamento (habilidade, hábitos e pontos preferenciais de pesca), além de episódios marcantes em suas histórias de vida (emalhes, desaparecimentos temporários, acidentes com pescadores, procriações). As características físicas e os hábitos comportamentais permitem o reconhecimento de cada animal e alguma previsibilidade na interação de pesca. A este respeito, são comuns analogias com pessoas, animais domésticos e de criação. "Se o senhor comprar cinquenta gados, ver eles crescer, não vai saber quem é um por um? Se o senhor tiver trigêmeos não vai saber quem é quem?”28.

Figueiredo, que é uma fêmea ${ }^{29}$, tem um cortezinho na galha (nadadeira dorsal). Scooby é branquicento, maior e tem uma mancha no meio da nadadeira dorsal. Caroba tem uma mancha branca desde filhote na lateral da nadadeira, além de uma outra marca no corpo, oriunda de um incidente com um pescador. A Botinha do Rio

é toda pretinha, não tem mancha nenhuma. É uma bota nova. [...] [Eletrônico] tem um cortezinho bem no comecinho da galha [...] e jeitinho de macho. [Mandalão tem um] risco branco na galha. Scooby tem só um, Mandalão tem dois. [A Borrachinha] tem um pingo branco do lado da galha. Borrachinha é filho da Borracha, uma bota boa que trabalha lá em cima no rio [Tubarão]. Ela também tem uma mancha na galha ${ }^{30}$.

O comportamento de cada animal é igualmente importante. Na Tesoura, "cada boto tem sua mania". "Às vezes, o boto não precisa nem mostrar o peixe, a gente conhece só pelo jeito dele virar no alagado. Como nós, cada um tem um jeito, igual um jeito de andar"3r. Alguns pescadores descrevem detalhadamente os hábitos de pesca desses animais, o modo como se posicionam em relação aos cardumes e sinalizam a presença deles. "Tem boto que deixa o peixe atrasado. Tem boto que deixa o peixe adiantado. Tem outros que deixam assim do ladinho do corpo" ${ }^{32}$. Caroba, por exemplo, "é uma bota mais calma e sorrateira, que pula fazendo a volta" 33 .

É possível que essa identificação seja recíproca. Pescadores de Barra de Imbé/

27 DAURA-JORGE, F., op. cit., p. 9.

28 Depoimento de Amilton, junho de 2015.

29 É relativamente comum botas boas com nomes masculinos, como a Figueiredo e a Taffarel.

30 Depoimento de Manoel, maio de 20I5.

3I Depoimento de Safico, junho de 2015.

32 Depoimento de Safico, junho de 2016.

33 Depoimento de Jader, maio de 2015. 
Tramandaí (RS) afirmam que os botos têm predileções por alguns pescadores, mostrando-lhes mais peixes ${ }^{34}$. Alguns pescadores também possuem botos de preferência. Um senhor muito experiente ali, apelidado Cinza, diz gostar mais do Scooby por ser um boto "que não mente. [Scooby] vem e pula, pode jogar que é peixe" 35 . Já Barroso prefere a Borracha, que foi quem lhe "deu" a maior tarrafada de sua vida, 297 tainhas em um único lanço. Quando ela surge outros pescadores podem brincar: "olha, Barroso, lá vem teu boto, é a Borracha". Considerando que alguns daqueles pescadores e botos, ao menos em Laguna, convivem há cerca de trinta anos, a questão do reconhecimento se torna menos enigmática.

Os animais são nomeados ainda filhotes, normalmente quando surge uma marca em seu corpo ou são acidentalmente capturados nas tarrafas. Quando isso ocorre, a iniciativa imediata dos pescadores é desenredá-los. Antigamente, se um filhote fosse acidentalmente capturado, marcava-se a nadadeira dorsal para reconhecimento posterior, o que não se faz mais.

Os nomes dos botos são relacionados ao parentesco (o filhote da Borracha, por exemplo, é Borrachinha); a personagens de cinema, televisão, futebol e política (Batman, Taffarel e Juscelino); a traços de comportamento (Ligeirinho); ao lugar de origem (Araranguá); à relação com algum pescador (Caroba leva o apelido do pescador que o viu pela primeira vez), além de outras associações, como com uma antiga marca de cigarro (Marusca).

Os botos podem ser chamados por nomes diferentes de acordo com o ponto de pesca. O filhote de Figueiredo é conhecido como Eletrônico, na Tesoura; Laguninha, na Toca da Bruxa; Surfistinha ou Lagartixa, em outros lugares. Além disso, um mesmo boto pode receber diferentes apelidos em um mesmo local, dependendo da criatividade do pescador. Na Tesoura, Scooby é também chamado de Garanhão, Sombra ou Bruxo devido às suas atitudes territorialistas e ao seu modo de trabalhar, submergindo e ressurgindo em lugares insuspeitos do canal. Isso indica uma imensa individuação desses animais, sempre associados às suas relações com pescadores e locais específicos.

\section{AtraÇão e entendimentos mútUOS}

Os pescadores só sabem, por meio dos botos, o local e o momento exato de lançar as tarrafas porque alguma forma de comunicação se estabelece entre eles. É preciso abandonar aqui o entendimento de comunicação limitado à linguagem verbal em prol de uma definição que abrange outros processos em que os comunicantes se influenciam, voluntária ou involuntariamente, por meio da transmissão de alguma forma de sinal.

34 ZAPPES, C. et al., op. cit., p. 430.

35 Depoimento de Cinza, julho de 2015. 
A esse respeito, Gregory Bateson ${ }^{36}$ contrasta a linguagem verbal exclusivamente humana com a comunicação baseada em sinais cinésicos e paralinguísticos, comum a todos os mamíferos (inclusive humanos) e a outros animais (como polvos). Tais sinais correspondem a movimentos e posturas corporais, tensões musculares; hesitações, pausas e acelerações; alterações de voz, respiração e expressão facial, entre outros. Os sentidos desses sinais na comunicação são determinados pelo contexto e por variações de magnitude - diferenças de amplitude, intensidade, velocidade e/ou duração ${ }^{37}$. Trata-se do que o autor chama de comunicação analógica, e ostensiva, na qual o objeto é apontado e usado como seu próprio referente. Por exemplo, "um mordisco de brincadeira entre cães denota mordida, mas não o que seria denotado pela mordida" ${ }^{8}$. Tais comportamentos sugerem algo (no caso, ataque), mas significam algo diferente (brincadeira). São "ações metafóricas" que comunicam e (reforçam) padrões de relacionamento análogos aos de outras relações ${ }^{39}$. Configura-se uma espécie de jogo metacomunicativo, em que os comportamentos sempre comunicam algo a respeito das contingências e padrões de relacionamento entre os interlocutores, como autoridade, submissão, dependência e brincadeira. Isso requer dos participantes deduzir o conteúdo das mensagens com base no contexto da interação, na relação entre eles e na experiência prévia de cada um. A situação emergente depende da forma como os comunicantes apreendem responsivamente os sinais uns dos outros.

Em contrapartida, a linguagem verbal humana baseia-se amplamente em codificação digital, um sistema de sinais discretos que possuem, em geral, uma relação arbitrária e convencional com seus referentes, e são organizados conforme alguma sintaxe. Ela nos possibilita não só fazer generalizações e abstrações, como discorrer sobre outros assuntos que não apenas a relação entre os interlocutores ${ }^{40}$. Os humanos utilizam as duas formas de comunicação conjuntamente, em reforço mútuo ou contradição. Desse modo, podem falar sobre outros assuntos e, ao mesmo tempo, sobre os padrões e contingências da relação entre os interlocutores.

Segundo Bateson, a evolução da vida nos oceanos teria limitado os recursos de golfinhos e demais mamíferos aquáticos no que diz respeito à comunicação cinésica e paralinguística. Seus corpos, como um bloco sólido, estariam privados da expressividade de partes separadas. Nesses animais, supõe o autor, a vocalização

36 BATESON, G. Steps to an ecology of mind. Collected essays in anthropology, psychiatry, evolution, and epistemology. Northvale (NJ): Jason Aronson Inc., I972; BATESON, G. Mind and nature: a necessary unity. New York: Hampton Press, I979.

37 Idem, I972, op. cit., p. 378-379; I979, op. cit., p. III.

38 Idem, I972, op. cit., p. I85-I86.

39 Por exemplo, o caso do líder da alcateia que repreende o jovem que cortejou uma fêmea do bando empurrando com a mandíbula a cabeça deste para o chão como os indivíduos adultos fazem com seus filhotes no desmame. Tal comportamento significa "eu sou um macho adulto e você é um filhote", e não "não faça isso". Da mesma maneira, a gata de estimação que se esfrega nas pernas de seu dono para lhe pedir comida, como um filhote para com sua mãe, comunica “dependência”, não "[quero] comida”. BATESON, G., I972, op. cit., p. 370-372.

40 Ibidem, p. 185 -I86. 
teria assumido preponderância nas funções comunicativas desempenhadas nos mamíferos terrestres por expressões faciais, movimentos de orelhas e cauda, pelos eriçados, punhos cerrados etc. ${ }^{4}$. Recentes estudos de bioacústica em Laguna têm assinalado o aumento e a variação no repertório de assobios e ecolocalizações dos botos bons durante a "pesca cooperativa" ${ }^{2}$. Os assobios emitidos pelos botos bons durante a pesca parecem exercer outras funções além da autoidentificação de cada boto, distinguindo-se tanto dos assobios utilizados pelos mesmos indivíduos em situações de forrageio sem os pescadores quanto daqueles emitidos por botos ruins $^{43}$. De modo semelhante, é possível que as ecolocalizações desempenhem outras funções além da localização das presas, como identificar a posição dos pescadores, direcionando o cardume; reconhecer o local onde as tarrafas foram lançadas, evitando emalhes; afugentar os peixes em direção aos pescadores ou atordoá-los de modo a facilitar a captura. Assobios e emissões de ecolocalização durante a pesca dizem respeito à comunicação direta entre os botos e destes com os peixes. Embora não sejam percebidas diretamente pelos pescadores, os efeitos dessas frequências acústicas são notados sob a forma das ações dos botos. Os pescadores deduzem a localização e o comportamento dos cardumes por meio da movimentação dos botos e, em menor medida, de aves, restolhos e brilheiros (alterações de textura e reflexos provocados pelos peixes na superfície da água).

As ideias de Bateson sobre comunicação nos ajudam a pensar as relações entre pescadores e botos pelo menos sob dois aspectos. O primeiro diz respeito ao deslocamento da ênfase na comunicação verbal para aquela cinésica e paralinguística. Os sinais dos botos bons para os pescadores consistem invariavelmente em movimentos corporais. O segundo refere-se à conceituação dessa forma de comunicação como analógica, já que botos mostram o peixe por meio de gestos que não constituem um repertório excepcional, mas cuja significação é estabelecida por diferenças de contexto e magnitude. Biólogos que trabalham com essa população apontam "sinais particulares": exibição do dorso, emersão parcial, batida com a cabeça e com a cauda ${ }^{44}$. De fato, os botos se movimentam, mergulham e exibem partes do corpo (sobretudo, o dorso e a cauda) no momento da sinalização, mas não de forma demasiado incomum. Para mostrar peixe, tais movimentos são mais fortes, mais enérgicos, como dizem os pescadores. Portanto, o que é particular à sinalização não são os tipos de movimento, mas suas magnitudes. Além disso, o sinal do boto para o arremesso das tarrafas é o clímax de uma sequência de movimentos significativos, "marcadores de contexto", que já indicavam a presença do peixe e a iminência da sinalização final. Antes, os botos já se aproximaram, "cheiraram peixe na pedra", cercaram o cardume. Portanto, os gestos para mostrar peixe são particulares, não ao repertório total de movimentos desses animais, mas ao contexto de cada lanço.

Os pescadores também sinalizam para os botos, intencionalmente ou não, sua presença no canal e intuito de pesca. Seus passos pelo banco de areia, a presença

4I Ibidem, p. 376.

42 ROMEU, B., 20I2, op. cit.; ROMEU, B., 20I5, op. cit., p. 99-IO0.

43 Idem, 20I5, op. cit., p. 99-I00.

44 SIMÕES-LOPES, P. C.; DAURA-JORGE, F.; CANTOR, M., op. cit., p. I. 
de seus corpos dentro d'água e sua movimentação acima e abaixo da superfície são notados pelos botos. Para redirecionar o cardume e chamar a atenção de botas e botos bons, os pescadores batem as chumbadas das tarrafas na superfície da água. Esse gesto deve ser estrategicamente utilizado, sob o risco de confundir os botos e interferir negativamente na pesca. Quando o boto sinaliza a localização do cardume, os pescadores devem lançar suas tarrafas. "Se o boto mostrar o peixe uma, duas, três vezes e o cara não botar [arremessar] a tarrafa, o boto larga o peixe” 45 . A resposta do pescador - não lançar a tarrafa ou lançá-la no momento exato, adiantado ou atrasado - é sempre apreendida pelo boto como informação (feedback) para se reajustar à ação em curso, continuar ou não a interação com o pescador. Ao longo da ação, pescadores e botos deduzem e respondem aos sinais uns dos outros. A situação emergente é ainda mais complexa se considerarmos que botos e pescadores comportam-se de forma responsiva também aos movimentos de peixes, marés, fluxos hídricos, vento e outros fatores ambientais. Os movimentos ajustam-se mutuamente, configurando uma cadeia de ações circular e multilinear. Isso requer de botos, botas e pescadores uma aprendizagem complexa, "aprender a aprender"46, isto é, responder de maneiras distintas aos "mesmos" sinais, conforme o contexto.

\section{COAPRENDIZAGEM E DESENVOLVIMENTO INTERESPECÍFICO DE HABILIDADES}

Não há muitas informações sobre a origem e a história da pesca conjunta em Laguna. Registros da cidade afirmam que ela teria começado em I84747, e estimativa recente reforça sua existência naquela época $4^{4}$. Segundo Safico:

Antes não tinha o canal, muita gente tarrafeando. $O$ mar cobria isso aqui tudo. Tinha só um pedacinho de terra e muita gente com tarrafa. $\mathrm{O}$ boto foi chegando e um foi se acostumando com o outro. Onde tem rede de espera, o boto não chega. Mas, com a tarrafa, o boto se aproxima 4 .

Com base na memória dos pescadores que frequentam a praia da Tesoura, foram retraçadas algumas genealogias de botos e botas boas em Laguna, com profundidade de até cinco gerações. Se é correta a estimativa de que tal pesca existe há cerca de I70 anos, há ainda outras tantas gerações ascendentes.

Especialistas afirmam que a "aprendizagem social" é mais relevante do que fatores ambientais e genéticos nessa "tática de forrageio" ${ }^{50}$. Tal hipótese baseia-se em

\footnotetext{
45 Depoimento de Barroso, junho de 2016.

46 BATESON, G., I972, op. cit., p. 279.

47 PRYOR, K. et. al., op. cit., p. 325.

48 Uma senhora nascida por volta de I903 contara que o avô dela já tarrafeava com os botos em Laguna (Pedro

Volkmer Castilho, comunicação pessoal, maio 20I5).
}

49 Depoimento de Safico, junho de 2016.

50 SIMÕES-LOPES, P. C.; DAURA-JORGE, F.; CANTOR, M., op. cit., p. I. 
três evidências: há golfinhos ali que nunca se envolveram no forrageio cooperativo; essa prática organiza a população de golfinhos em dois grupos distintos, "cooperados" e "não cooperados" 5 ; se não fosse a aprendizagem social, os golfinhos teriam a cada nova geração que recriar individual e independentemente tal comportamento, que se apresenta de forma bastante inalterada ao longo de diferentes gerações ${ }^{52}$. Para Pryor e colaboradores, "Laguna's 'good' dolphins may represent an example of a culturally transmitted fishing specialization"53.

Segundo pescadores e biólogos, botas boas tendem a gerar botas e botos bons. O comportamento cooperativo dos botos seria transmitido, sobretudo, pelas mães aos filhotes, que imitam seus movimentos ${ }^{54}$. Tanto pescadores quanto biólogos relatam ter observado mães incitarem seus filhotes em direção aos peixes 55 .

Cada bota e boto bom tem sua forma de trabalhar. Há diferenças de destreza que se devem ao tempo tanto de prática quanto de socialização com indivíduos mais experientes. Privado do convívio mais próximo e prolongado com uma bota boa, um filhote jamais desenvolveria tal comportamento espontaneamente. Considere-se o caso de Sacolão, que tem aproximadamente 20 anos de idade e é a última filhote de Latinha. "[Sacolão] Trabalha muito pouco. Uma vez ou outra, dá um pulinho. Mas é muito ruim. Quando Latinha morreu, ela era muito nova"56. Diferente dela, sua irmã mais velha, Taffarel, conviveu o suficiente com a mãe, dando continuidade a uma linhagem de botas e botos bons: Borracha e Ligeirinho, na primeira geração descendente; Batman, Robin e Capinha, na segunda.

A aprendizagem com botos e botas mais experientes pode levar à especialização em determinada forma de pesca. É o caso de Botinha do Rio e sua filha, Princesa. Ambas trabalham mais lá no rio e são reputadas na batida ${ }^{57}$. Chega Mais, a irmã de Botinha do Rio, faleceu há cerca de dez anos e é lembrada pela destreza nessa técnica de pesca. Não por acaso, todas elas descendem de Inrilha, uma bota que também "trabalhava mais lá no rio, na batida".

Algo semelhante ocorre com a aprendizagem dos pescadores. Filhos e netos de pescadores, muitos deles afirmam ter começado a pescar bastante cedo. De forma análoga às relações de botos e botas boas com suas progenitoras, a aprendizagem

5I DAURA-JORGE, F., op. cit.

52 Ibidem, p. 2-3.

53 PRYOR, K. et al., op. cit. , p. 33 I.

54 Para situação semelhante cf. MANN, J. et al. Social networks reveal cultural behaviour in tool-using dolphins. Nat Commun, n. 3, 2012, p. 980, 2012.

55 STRAIN, D. 20I2. Clues to an Unusual Alliance Between Dolphins and Fishers. May. I, 20I2. American Association for the advancement of Science. Disponível em: <news.sciencemag.org/2012/05/clues-unusual-alliance-between-dolphins-and-fishers $>$. Acesso em: 30 jan. 2018.

56 Depoimento de Gegê, maio de 2015.

57 Batida é uma técnica de pesca com os botos que acontece na foz do rio Tubarão. Nela, os botos aglomeram os peixes em frente às canoas, antes de sinalizar a sua localização e o momento oportuno para lançar as tarrafas. Cf. PETERSON, D., op.cit., p. I8-20. 
desses homens depende da convivência com pescadores mais experientes ${ }^{5}$. Nota-se, contudo, uma curiosa inversão de gênero entre as espécies. Se, no caso dos golfinhos, a principal referência para aprendizagem são matrilinhagens de botas boas, no caso dos homens, são patrilinhagens de pescadores.

Evidentemente, alguns dos conhecimentos necessários aos pescadores são diferentes daqueles imprescindíveis a botas e botos bons. Além da resistência física e psicológica para longas esperas na água fria, os primeiros precisam saber manusear bem as tarrafas; identificar os índices da presença de botos e tainhas (saltos, restolhos, brilheiros e outras perturbações na água), bem como seus comportamentos; conhecer os efeitos de arranjos variados de ventos e marés; e, finalmente, reconhecer a sinalização dos botos. Já os botos e botas boas têm que saber localizar e conduzir os cardumes em direção aos pescadores, coordenar suas ações, sinalizar o momento e o local para o arremesso das tarrafas e evitar possíveis emalhes.

Dessa perspectiva, a pesca conjunta em Laguna se perpetuaria por duas linhas verticais e paralelas de transmissão intergeracional de conhecimentos distintos e exclusivos a cada espécie. Porém, há pelo menos três aspectos correlacionados dessa forma de pesca que sugerem outro entendimento do fenômeno:

I. A aprendizagem não envolve apenas indivíduos de gerações adjacentes mãe, filhos e filhas, entre os golfinhos; avôs, pai e filhos, entre os pescadores. Pesquisadores consideram haver "aprendizagem horizontal" 59 , e pescadores relatam casos de botos com idades aproximadas que andavam juntos e começaram a trabalhar na mesma época. Aventa-se a possibilidade de o conhecimento dessa pesca estar sendo levado por animais de Laguna àqueles do rio Tramandaí ${ }^{60}$. De modo semelhante, é possível que Porquinho e Araranguá, botos oriundos de Tramandaí e Araranguá, tenham começado a participar da pesca após migrarem para Laguna. Tal aprendizagem se dá por meio de convívio, observação e imitação de indivíduos mais experientes, que também estão desenvolvendo conjuntamente a habilidade, o que é igualmente válido para os pescadores.

2. Os conhecimentos de botos e pescadores não constituem roteiros predeterminados, procedimentos anteriores e independentes da ação e do contexto. Ainda que exista certo "receituário" entre humanos, este só adquire sentido na prática e não abrange todos os aspectos perceptuais, motores e comunicativos envolvidos. A aprendizagem é constante e progressiva, ao longo de sucessivas experimentações práticas, em um contexto marcado pela convivência entre os praticantes de ambas as espécies. Por isso, propomos pensar os conhecimentos

58 SIMÕES-LOPES, P. C.; DAURA-JORGE, F.; CANTOR, M., op. cit., p. 2.

59 SIMÕES-LOPES, P. C.; FÁBIAN, M. E.; MENEGHETI, J. O., op.cit.

60 ROSA, E. Esgotamento dos cardumes aumenta disputa entre homens, aves e mamíferos pelos recursos naturais. Notícias do Dia, 20I3. Disponível em: <ndonline.com.br/florianopolis/noticias/70435-esgotamentodos-cardumes-aumenta-disputa-entre-homens-aves-e-mamiferos-pelos-recursos-pesqueiros.html $>$. Acesso em: 30 jan. 2018. 
envolvidos na pesca conjunta como habilidades ${ }^{6 \mathrm{r}}$. Para Ingold, as habilidades seriam modos particulares de percepção e ação que emergem nas práticas pelas quais os sujeitos engajam-se no mundo. Elas se definem pelo ajuste constante de movimentos conforme o monitoramento perceptual contínuo da tarefa emergente e a exploração ativa das possibilidades ambientais. Sua aprendizagem se dá por meio de uma "educação da atenção"62, a sintonização dos sistemas de percepção-ação dos praticantes com aspectos do ambiente. Irredutíveis à informação transmissível, tais habilidades são cultivadas por botos e pescadores principiantes por meio de prática continuada e conforme eles acompanham atentamente as orientações, demonstrações e ações de botos e pescadores mais experientes. Cada gesto, de botos e pescadores, é sempre um ato de imitação e improviso. Imita-se as ações bem-sucedidas anteriormente executadas por si mesmo e por praticantes mais experientes. Ao fazê-lo, improvisa-se, já que as circunstâncias de cada ato nunca são exatamente iguais às anteriores. Há sempre diferenças no ambiente, de marés e correntes, ventos, peixes, pescadores e botos. Trata-se de "redescoberta guiada" ${ }^{63}$, pois demonstrar uma prática é presentificá-la para alguém, de modo que possa ser aprendida diretamente, sentindo, experimentando ${ }^{64}$. Portanto, o legado das gerações ascendentes de botos e pescadores não é um conjunto de regras ou esquemas para comportamentos apropriados, mas as condições específicas para o desenvolvimento de tais habilidades por seus sucessores ${ }^{65}$.

3. O desenvolvimento das habilidades implicadas nessa pesca não se limita, de um lado, a humanos entre si, de outro, a golfinhos entre eles. Os botos aprendem a pescar com outros botos, e também com os pescadores. Os pescadores aprendem a pescar com outros pescadores, e também com os botos. Exemplo disso, às avessas, é o que tem acontecido na batida (ver nota 57). "Hoje, está cheio de gurizão pescando lá no rio. Mas eles não esperam o boto bater o peixe. Com qualquer saltinho, já estão botando a tarrafa. [Por conseguinte,] os botos novos não estão mais aprendendo a bater o peixe"66. O lançamento antecipado da tarrafa interrompe a sequência de movimentos e, no limite, a possibilidade de os novos golfinhos desenvolverem tal habilidade.

Para além dos conhecimentos específicos de botos e pescadores, ambos precisam saber emitir, perceber e deduzir os sentidos de sinais recíprocos. Essa responsividade mútua e a sintonização das ações são as principais habilidades desenvolvidas.

6I INGOLD, T. The perception of the environment: essays on livelihood, dwelling and skill. London and New York: Routledge, 2000; INGOLD, T. Da transmissão de representações à educação da atenção. Educação, v. 33, n. I, 20Io, p. 6-25.

62 GIBSON, James. The ecologycal approach to visual perception. New York: Psychology Press, I986, p. 254.

63 INGOLD, T., 2000, op. cit., p. I46, 387; 2010, op. cit., p. I9.

64 Idem, 20IO, op. cit., p. 2I.

65 Idem, 2000, op. cit., p. 387.

66 Depoimento de Barroso, junho de 2016. 
Pescadores, botos e botas desenvolvem e perpetuam conjuntamente essa forma de pesca. Não se trata de uma prática reproduzida por interação de heranças culturais transmitidas em duas linhas verticais e paralelas - de um lado, a série humana, de outro, a série animal. A pesca conjunta surgiu e tem se desenvolvido a partir do entrelaçamento e da co-constituição das linhas de vida de botos, peixes e pescadores.

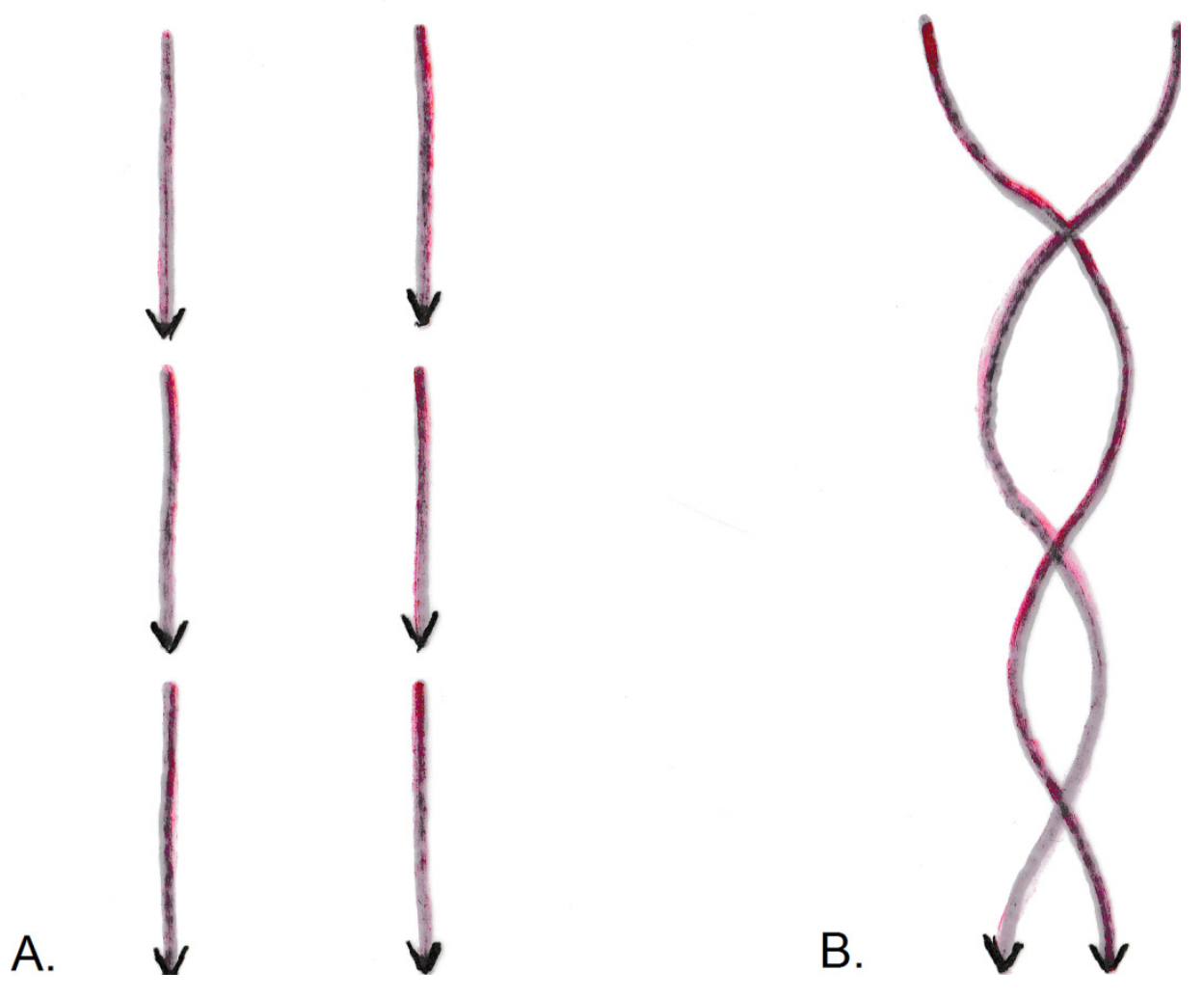

Figura 5-(A) transmissão intraespecífica; (B) coaprendizagem interespecífica. Ilustração: Gabriel Coutinho Barbosa 


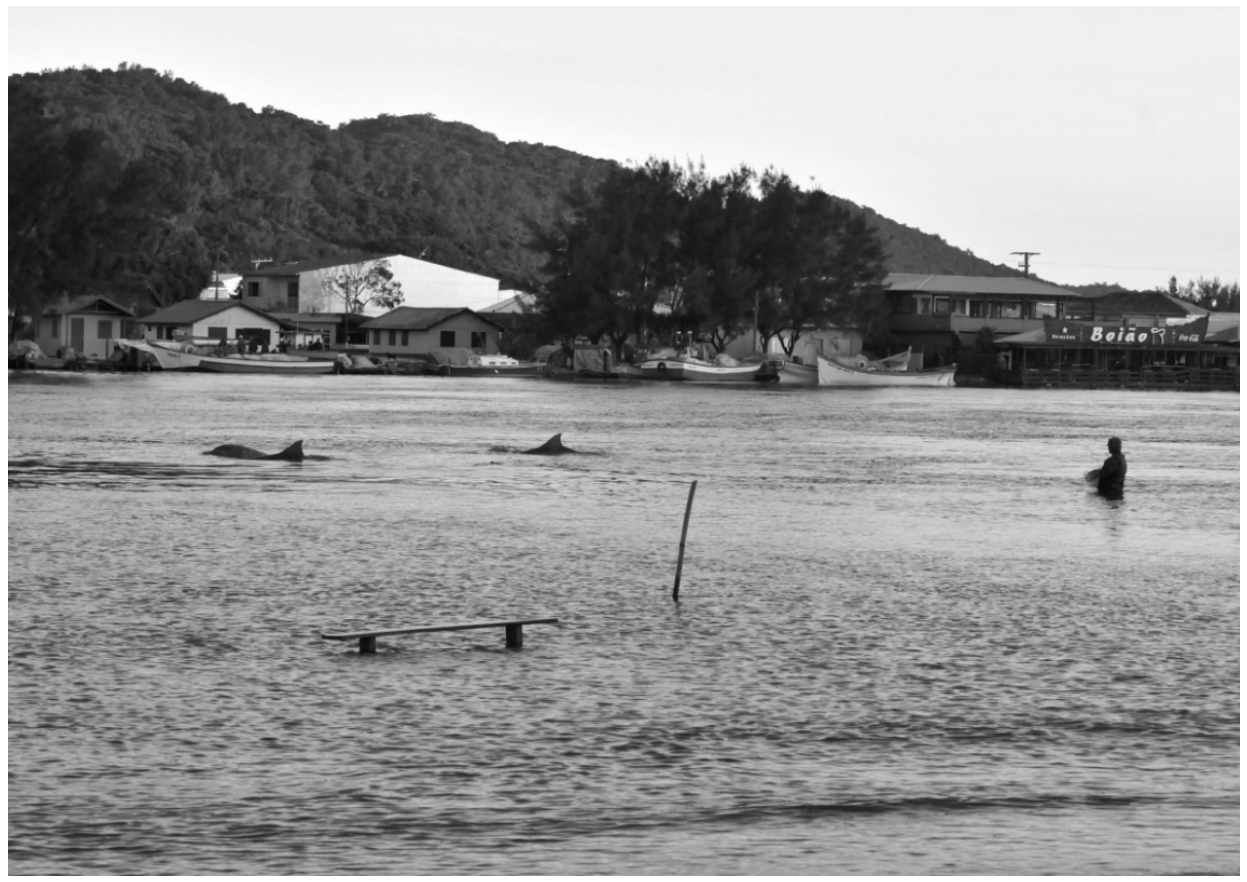

Figura 6 - Fim de tarde na Tesoura (inverno 20I6). Foto: Brisa Catão

SOBRE OS AUTORES

BRISA CATÃO é doutoranda em Antropologia Social na Universidade Federal de Minas Gerais (UFMG), com formação complementar na University of New South Wales (UNSW) e pesquisadora do Laboratório de Antropologia das Controvérsias Sociotécnicas.

E-mail: brisacatao@gmail.com

GABRIEL COUTINHO BARBOSA é professor do Departamento de Antropologia, Programa de PósGraduação em Antropologia Social da Universidade Federal de Santa Catarina.

E-mail: ggabrielbar@gmail.com 


\section{REFERÊNCIAS BIBLIOGRÁFICAS}

BATESON, Gregory. Steps to an ecology of mind. Collected essays in anthropology, psychiatry, evolution, and epistemology. Northvale (NJ): Jason Aronson Inc., I972.

. Mind and nature: a necessary unity (advances in systems theory, complexity, and the human sciences). New York: Hampton Press, I979.

BUSNEL, R. G. Symbiotic relationship between man and dolphins. Transaction New York Acad. Sci., n. 35, I973, p. II2-I3I.

CLODE, Danielle. Killers in Eden: The true story of killer whales and their remarkable partnership with the whalers of Twofold Bay. Sydney (Australia): Allen \& Unwin, 2002.

DAURA-JORGE, Fábio G. Quantos? Onde? Como? Múltiplos aspectos ecológicos de uma população do boto-da-tainha (Tursiops truncatus) em Laguna, sul do Brasil: implicações para conservação. $20 I I$. Tese (Doutorado em Zoologia). Programa de Pós-Graduação em Ciências Biológicas - Zoologia, Universidade Federal do Paraná, $20 I I$.

D'LIMA, C. et al. Positive interactions between irrawaddy dolphins and artisanal fishers in the Chilika Lagoon of Eastern India are driven by ecology, socioeconomics, and culture. Ambio a Journal of the Human Environment, v. 43, n. 5, p. 614-624, 2013.

GIBSON, James. The ecologycal approach to visual perception. New York: Psychology Press, I986.

IINO, Fátima. Pescadores artesanais na Praia da Tesoura, Laguna/SC: reflexões sobre sociabilidades e apropriações do espaço. Dissertação (Mestrado em Antropologia Social). Universidade Federal de Santa Catarina, 20I7.

INGOLD, Tim. The perception of the environment: essays on livelihood, dwelling and skill. London and New York: Routledge, 2000.

. Da transmissão de representações à educação da atenção. Educação, v. 33, n. I, 20Io, p. 6-25.

KILLER whales of Eden, Australia. Wikipedia. Disponível em: <en.wikipedia.org/wiki/Killer_whales_of_ Eden,_Australia>. Acesso em: I2 fev. 2016.

KILLERS of Eden - and darkness was upon the face of the deep. Killers of Eden. The incredible true history of the killer whales of Twofold Bay. Disponível em: 〈www.killersofeden.com〉. Acesso em: I2 fev. 2016.

LESTEL, D.; Brunois, F.; GAUNET, F. Etho-ethnology and ethno-ethology. Social Science Information, v. 45, n. 2, 2006, p. I55-I77.

MANN, J. et al. Social networks reveal cultural behaviour in tool-using dolphins. Nat Commun, n. 3, 20I2, p. 980.

MONTEIRO-FILHO, E. Pesca associada entre golfinhos e aves marinhas. Revista Brasileira de Zoologia, v. 9, n. I-2, I992, p. 29-37.

NEIL, D. T. Cooperative fishing interactions between Aboriginal Australians and dolphins in eastern Australia. Anthrozoos, n. I5, 2002, p. 3-I8.

PETERSON, D. Etnobiologia dos botos (Tursiops truncatus) e a pesca cooperativa em Laguna, Santa Catarina. Monografia (Bacharelado em Ciências Biológicas). Universidade Federal de Santa Catarina, 2005.

PETERSON, D.; HANAZAKI, N.; SIMÕES-LOPES, P. C. Natural resource appropriation in cooperative artisanal fishing between fishermen and dolphins (Tursiops truncatus) in Laguna, Brazil. Ocean Coast Manag., n. 5, 2008, p. 469-475.

PRYOR, K. et al. A dolphin-human fishing cooperative in Brazil. Marine Mammalogy Science, n. 6, I990, p. 325-332.

PRZBYLSKI, Cristiane B.; MONTEIRO-FILHO, Emygdio L. A. Interações entre pescadores e mamíferos marinhos no litoral do estado do Paraná - Brasil. Biotemas, v. I4, n. 2, 200I, p. I4I-I56. 
ROMEU, Bianca. Repertório acústico do boto-da-tainha no contexto da pesca cooperativa com pescadores artesanais em Laguna, sul do Brasil. Monografia (Bacharelado em Ciências Biológicas). Universidade Federal de Santa Catarina, 2012.

. Contribuições do comportamento acústico do boto-da-tainha (Tursiops truncatus) para o entendimento da interação entre botos e pescadores em Laguna, Santa Catarina. Dissertação (Mestrado em Ecologia). Universidade Federal de Santa Catarina, 20I5.

ROSA, Edson. Esgotamento dos cardumes aumenta disputa entre homens, aves e mamíferos pelos recursos naturais. Notícias do Dia, 20I3. Disponível em: <ndonline.com.br/florianopolis/noticias/ 70435-esgotamento-dos-cardumes-aumenta-disputa-entre-homens-aves-e-mamiferos-pelos-recursos-pesqueiros.html >. Acesso em: 30 jan. 2018.

. Novas gerações de botos e pescadores seguem ritual secular da pesca integrada de tainha em Laguna. Notícias do Dia, 20I5. Disponível em: <ndonline.com.br/florianopolis/noticias/249822-novas-geracoes-de-botos-e-pescadores-seguem-ritual-secular-da-pesca-integrada-de-tainha-em-laguna. html>. Acesso em: 30 jan. 2018.

SIMÕES-LOPES, P. C. Interaction of coastal populations of Tursiops truncatus (Cetacea, Delphinidae) with the mullet artisanal fisheries in Southern Brazil. Biotemas, n. 4, I99I, p. 83-94.

SIMÕES-LOPES, P. C.; FÁBIAN, M. E.; MENEGHETI, J. O. Dolphin interactions with the mullet artisanal fishing on Southern Brazil: a qualitative and quantitative approach. Revista Brasileira de Zoologia, $\mathrm{n}$. I5, I998, p. 709-726.

SIMÕES-LOPES, P. C.; DAURA-JORGE, F.; CANTOR, M. Clues of cultural transmission in cooperative foraging between artisanal fishermen and bottlenose dolphins, Tursiops truncatus (Cetacea: Delphinidae). Zoologia, v. 33, 2016, n. 6.

SMITH, B. D. et al. Catch composition and conservation management of a human-dolphin cooperative cast-net fishery in the Ayeyarwady River, Myanmar. Biol. Conserv., n. I42, 2009, p. I042-I049.

STRAIN, Daniel. Clues to an unusual alliance between dolphins and fishers. American Association for the advancement of Science, 20I2. Disponivel em: <news.sciencemag.org/20I2/05/clues-unusual-alliance-between-dolphins-and-fishers $>$. Acesso em: 30 jan. 2018.

VAN DOOREN, Thom; DESPRET, Vinciane. Evolution: Lessons from some cooperative ravens. In: TURNER, Lynn; BROGLIO, Ron; SELLBACHS, Undine (Ed.) The Edinburgh companion to animal studies. Edinburgh: University of Edinburgh. No prelo.

ZAPPES, C. et al. "Human-dolphin (Tursiops truncatus Montagu, I82I) cooperative fishery" and its influence on cast net fishing activities in Barra de Imbé/Tramandaí, Southern Brazil. Ocean er Coastal Management, n. 54, 20II, p. 427-432. 